\title{
Effect of the manual (GMAW) and pulsed (P-GMAW) welding processes on impact strength and fracture behavior of AISI 304-AISI 1040 dissimilar steel joints fabricated by ASP316L austenitic stainless steel filler metal
}

\author{
T. Teker ${ }^{*}$, T. Kurşun ${ }^{2}$ \\ ${ }^{1}$ University of Adiyaman, Faculty of Engineering, Department of Metallurgy and Materials Engineering, \\ 02040 Adiyaman, Turkey \\ ${ }^{2}$ University of Cumhuriyet, Faculty of Technology, Department of Manufacturing Engineering, 58140 Sivas, Turkey
}

Received 8 April 2015, received in revised form 10 February 2016, accepted 17 May 2016

\begin{abstract}
In this study, AISI 1040 steel and AISI 304 austenitic stainless steel sheets with $10 \mathrm{~mm}$ thickness were joined by the manual gas metal arc (GMAW) and the synergic controlled pulsed (P-GMAW) welding methods. The microstructural changes, phases, and compounds occurred in the interface of welded samples were comprehensively examined by using a combination of scanning electron microscopy (SEM), microanalysis by energy dispersive spectrometry (EDS), $\mathrm{X}$-Ray diffraction (XRD), and microhardness tests. To determine the mechanical properties of welded samples, notch impact strength tests were applied. In addition, fracture types in the notch impact test of samples were determined from the fractographic examinations by using SEM. At the end of these tests, the best result was obtained by the synergic controlled pulsed (P-GMAW) technique.
\end{abstract}

Key words: manual gas metal arc welding (GMAW), synergic controlled pulsed welding (P-GMAW), AISI 304, AISI 1040, microstructure

\section{Introduction}

Austenitic stainless steels represent the largest of the general groups of stainless steels and are produced in higher tonnages than any other group. They have good corrosion resistance in most environments. They are used in a wide range of applications, including structural support and containment, architectural use, kitchen equipment, and medical products. Austenitic stainless steels are widely used not only because of their corrosion resistance but because they are readily formable, fabricable, and durable [1].

Gas metal arc welding (GMAW) is a metal joining process, in which the arc is established between a continuous, consumable electrode wire and the metal being welded. The arc is shielded from contaminants in the atmosphere by the shielding gas such as carbon dioxide, argon, helium, etc. The welding current, arc voltage, and welding speed are the primary variables in any GMAW process. The auxiliary adjustable parameters are the welding torch angle, plate-to-nozzle distance, welding direction, shielding gas flow rate and its pressure. However, wire electrode diameter and its composition, polarity and its extension, base material composition, type of shielding gas, etc. are generally kept constant during welding. The P-GMAW can be used for any type of ferrous as well as nonferrous materials, even for sheet metal joining and positional welding, which is very much problematic with other welding processes. It can reduce hot cracking, corrosive tendency, spattering, and distortion due to pulsed nature of current. However, this process depends greatly on the right selection of pulse parameters, as the latter affect the weld microstructure and porosity content of the weld due to their influence on weld thermal cycle and arc characteristics. The appropriate selection of pulse parameters provides a droplet of required size with a suitable velocity to propel it

*Corresponding author: tel.: +90 416 2233800; fax: +90 416 2233809; e-mail address: tteker@adiyaman.edu.tr 
Table 1. Chemical composition of materials used in experiments (wt.\%)

\begin{tabular}{lcccccccccc}
\hline Material & $\mathrm{Fe}$ & $\mathrm{C}$ & $\mathrm{Cr}$ & $\mathrm{Ni}$ & $\mathrm{Si}$ & $\mathrm{Mo}$ & $\mathrm{S}$ & $\mathrm{Mn}$ & $\mathrm{P}$ & $\mathrm{Cu}$ \\
\hline AISI 304 & Bal. & 0.048 & 16.02 & 0.22 & 0.44 & 0.016 & 0.002 & 0.610 & - & - \\
AISI 1040 & Bal. & 0.39 & - & - & 0.158 & - & 0.022 & 0.65 & 0.034 & 0.31 \\
AISI 316L & Bal. & 0.03 & 18 & 12 & 0.7 & 2.5 & - & 0.8 & - & - \\
\hline
\end{tabular}

Table 2. Mechanical properties of materials used in experiments

\begin{tabular}{lccc}
\hline Material & Tensile strength $(\mathrm{MPa})$ & \% Elongation $(\mathrm{mm})$ & Hardness, HV \\
\hline AISI 1040 & 417 & 25 & 201 \\
AISI 304 & 515 & 40 & 185 \\
AISI 316L & 540 & 40 & 170 \\
\hline
\end{tabular}

Table 3. The process parameters used in experiments

\begin{tabular}{|c|c|c|c|c|c|c|}
\hline $\begin{array}{l}\text { Sample } \\
\text { No. }\end{array}$ & $\begin{array}{l}\text { Voltage } \\
(\mathrm{V})\end{array}$ & $\begin{array}{l}\text { Welding current intensity } \\
\text { (A) }\end{array}$ & $\begin{array}{l}\text { Welding speed } \\
\qquad\left(\mathrm{mm} \mathrm{s}^{-1}\right)\end{array}$ & $\begin{array}{l}\text { Wire feed rate } \\
\left(\mathrm{m} \mathrm{min}^{-1}\right)\end{array}$ & $\begin{array}{l}\text { Gas flow rate } \\
\quad\left(1 \mathrm{~min}^{-1}\right)\end{array}$ & Process \\
\hline S1 & 22.5 & 130 & 4 & 3.2 & 16 & GMAW \\
\hline $\mathrm{S} 2$ & 22.5 & 99 & 4 & 3.2 & 16 & P-GMAW \\
\hline
\end{tabular}

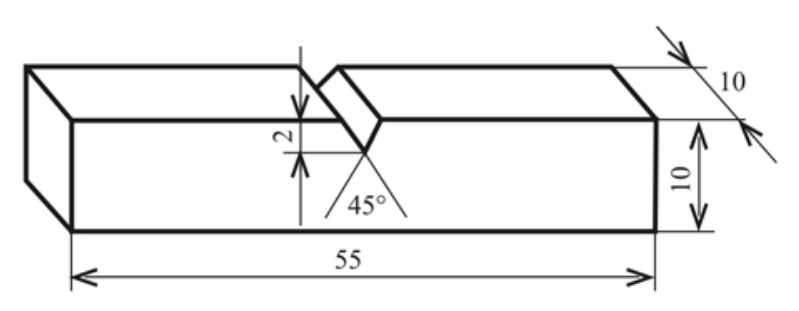

Fig. 1. The dimension of the V-notch impact test sample.

against gravity and fluidity of the weld pool, to achieve desired weld bead. All commercially important metals such as carbon steel, stainless steel, aluminum, and copper can be welded with this process in all positions by choosing the appropriate shielding gas, electrode, and welding conditions [2, 3]. The P-GMAW is versatile and easily automated. Thus, it is becoming increasingly popular for use in modern robotics and automated industries. Current pulsing has been used to obtain grain refinement in weld fusion zones, which has a positive contribution to mechanical properties [4].

Current pulsing has been used by several investigators to obtain grain refinement in weld fusion zones and improvement in weld mechanical properties. However, reported research work on relating the pulsed current parameters and tensile properties are very scanty [5-7].

The increasing importance of economic factors in recent years required the combination of materials with different properties. In this study, AISI
304 austenitic stainless steel, which is the most commonly used type of stainless steels, and AISI 1040 steel pairs were welded using manual (GMAW) and synergic controlled pulsed (P-GMAW) welding methods and ASP316L austenitic stainless steel additional wire. The effect of the selected welding methods on impact resistance and fracture behavior and the microstructure of welded joints were investigated in the study.

\section{Materials and method}

AISI 304/AISI 1040 steel couples of $10 \mathrm{~mm}$ thickness, and 316L austenitic stainless steel wire of $1 \mathrm{~mm}$ are used in experiments. The results of chemical analysis of these materials are listed in Table 1, and mechanical properties are given in Table 2 . The dimensions of samples are $100 \times 100 \times 10 \mathrm{~mm}^{3}$, and the samples have $60^{\circ} \mathrm{V}$ welding groove. GMAW and PGMAW were performed by MIGATRONIC KME 400 model automated welding machine. The mixture of Ar $+2 \% \mathrm{O}_{2}$ gas was used as shielding gas atmosphere. The welding speed was $4 \mathrm{~mm} \mathrm{~s}^{-1}$ and wire feed speed was set to $3.2 \mathrm{~m} \mathrm{~min}^{-1}$. The welding voltage was 22.5 $\mathrm{V}$, and a constant gas flow rate of $16 \mathrm{lmin}^{-1}$ was selected. Welding parameters used in this study are listed in Table 3 . The welding was carried out by filling the weld groove in multi-passes ( 2 passes) at the top and in a single pass at the bottom for each other. Samples were ground with mesh size 80-1200 for microstructure analysis and polished with $3 \mu \mathrm{m}$ diamond 
paste. Then, AISI 304 side of samples was etched electrolytically in a solution of $50 \% \mathrm{HNO}_{3}+50 \%$ pure alcohol and 12 V. AISI 1040 side of samples was etched by a chemical etching method with $2 \% \mathrm{HNO}_{3}+98 \%$ pure alcohol. Microstructural changes on welding interface were examined by LEO EVO 40XVP SEM device. Microhardness measurements of samples were carried out at an interval of $0.5 \mathrm{~mm}$ on a load of $200 \mathrm{~g}$ with HV hardness scale. Leica MHT-10 testing machine was used for measurements. EDS analysis of the elementary content of phases on the interface of samples, welded by GMAW-P method, was performed using BRUKER $125 \mathrm{eV}$ device. In order to determine the phases and compounds on samples, XRD analysis was carried out through SHIMADZU XRD-6000 equipped with a $\mathrm{Cu} \mathrm{K} \alpha$ /tube, wavelength of $(\lambda=) 1.54056 \AA$, voltage of $40 \mathrm{kV}$ and ampere of $40 \mathrm{~mA}$. Impact test samples were prepared for the mechanical examination of the welds. Then the samples were tested by using a Wolpert PW30 notch Charpy test device with the hammer of $300 \mathrm{~J}$. In addition, fracture surface was examined by SEM after impact test.

\section{Results and discussion}

\subsection{Microstructure analysis}

Optical images showing the structural change in joint section of AISI 304 and AISI 1040 steel pairs which were welded using GMAW and P-GMAW welding methods are respectively presented in Figs. 2 and 3. Analysis of microstructures of S1 and S2 samples showed welding zone (weld metal, transition area and HAZ) microstructure images of the joint. Microstructure image taken in the interface region of the S1 and $\mathrm{S} 2$ welded samples showed that there were no cracks, voids or unconnected regions in two transit zones adjacent to the weld pool. It was observed that from weld metal to AISI 1040 base metal, grain coarsening occurred due to the annealing effect by heat input and then it turned into the fine-grained homogenous region in the remaining section of the structure which was affected by fast cooling. It is indicated in Fig. 3 that no grain coarsening was observed in welding which used P-GMAW welding method while the welding which used MIG method showed significant grain coarsening. It was observed that grain sizes of weld metal were different due to different heat input in GMAW and P-GMAW welded joints. Normally, as heat input is high in GMAW welding, larger-grained structure forms. However, the performance of GMAW welding in inverter type welding machine and under pulsed current decreased heat input and hardening of the structure in fine-grained form. It was observed that austenitic base metal grains were elongated in the direction of the roll. In heat affected zone (HAZ), AISI
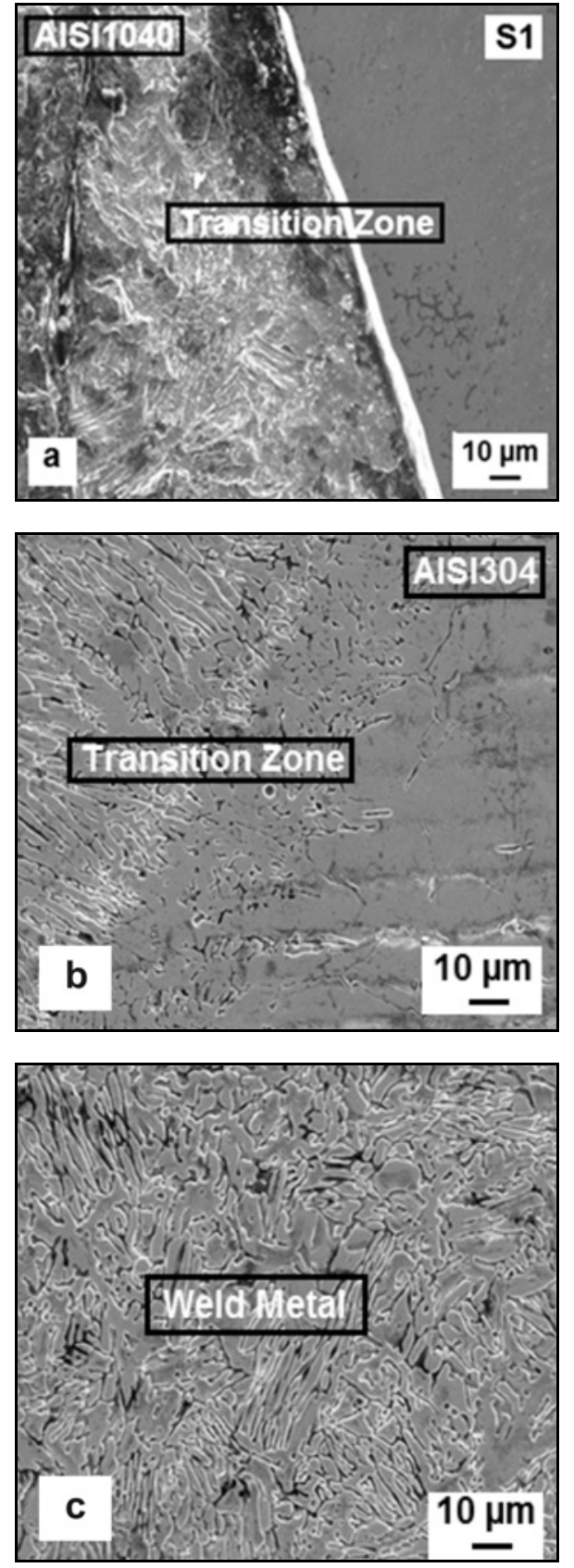

Fig. 2a-c. The SEM micrographs taken from the welding interface of sample S1.

1040 steel has partially molten narrow region extending to the base metal and a high amount of acicular ferrite structures. There is an intense lath martensitic structure in transition region adjacent to the molten metal. In the large-grained region, there is a structure composed of a high number of Widmanstätten ferrite and acicular ferrite starting from grain boundaries. Analysis of weld metal microstructures showed that grain coarsening increased in parallel to increased heat input; hardening of weld metal occurred towards welding central line, and that molten-hardened grains elon- 

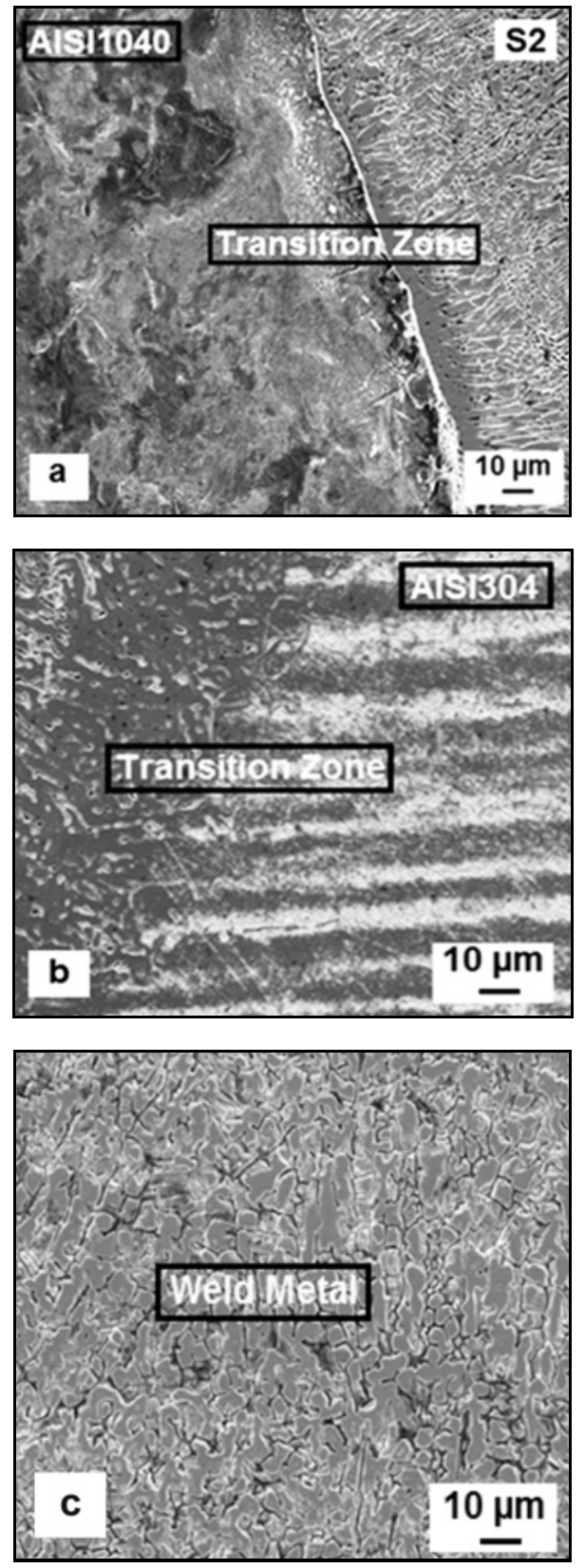

Fig. 3a-c. The SEM micrographs taken from the welding interface of sample S2.

gated in heat flow direction. The seams in both samples were dendritic and equiaxial. It was observed that one seam tempered the previous one. Microstructure images showed that HAZ was martensite and residual in austenite regions adjacent to the seams and that tempering heat procedure spheroidized the martensite. The seams have an austenitic phase structure since austenitic weld addition metal was used especially in the seam structure. Previous studies on welding on austenitic stainless steels showed that grain coarsening increased in parallel with the increase of heat input and that the grains elongated according to heat flow $[8,9]$. These microstructure changes occurred due to the different chemical composition of different welded metals, different melting, mixture, and cooling, and different thermal conduction coefficients of the base material. Furthermore, it was found that the grains near the melting limit of the austenitic stainless steel side of the welding had a similar appearance with the weld metal grains; however, grain elongation was not regular due to the complexity of heat in this region. Analysis of the region near melting limit of the austenitic stainless steel side of the welding showed that the grains in this region did not have a similar appearance with the grains in weld metal as they were composed of a mixture of austenitic additional weld metal + carbon steel base metal. As indicated in Fig. 4, X-RD analysis of $\mathrm{S} 2$ sample showed ferrite, austenite, $\mathrm{Cr}_{7} \mathrm{C}_{3}$ compounds. Precipitation of these carbide particles provides distribution strengthening; however, it also causes brittleness.

Schaeffler diagram was used to evaluate the textures of the samples in the seam, HAZ, and main structure. Nickel and chrome equivalences of both the base metal and electrode were identified. The values obtained were transferred to Schaeffler diagram, and the points representing the base metal and the electrode were combined. Considering that the base metal will have a $30 \%$ contribution in the seams and root seam, the length of the line connecting these points from the point representing the base metal to the point representing the electrode was moved to $30 \%$ on the welding line, and the structure of this region was tried to be estimated. This calculation and microstructure results showed that the seam was mainly austenite in both samples. $\mathrm{Cr}$ and $\mathrm{Ni}$ equivalence and $\%$ ferrite ratios of the base metal and additional metal were calculated using the below formula. It was found that $\mathrm{Ni}_{\mathrm{eq}}=13.3$ and $\mathrm{Cr}_{\mathrm{eq}}=21.55$ for AISI $316 \mathrm{~L}$ weld additional metal and $\mathrm{Ni}_{\text {eq }}=10.58$ and $\mathrm{Cr}_{\text {eq }}=19.45$ for the AISI 304 base material. Weld metal was in austenite + ferrite zone while the base metal was in austenite + martensite + ferrite zone. The $\%$ ferrite ratio of 316L weld metal was $6.18 \%$ while the $\%$ ferrite ratio of AISI 304 was $6.64 \%$. Austenite + \% 5-10 ferrite ratio has a high corrosion resistance. It is not sensitive to cracking.

$$
\begin{gathered}
(\mathrm{Ni})_{\mathrm{eq}}=\% \mathrm{Ni}+30(\% \mathrm{C})+0.5(\% \mathrm{Mn}) \\
(\mathrm{Cr})_{\mathrm{eq}}=\% \mathrm{Cr}+\% \mathrm{Mo}+1.5(\% \mathrm{Si})+0.5(\% \mathrm{Nb}) \\
(\mathrm{Ni})_{\max }=\frac{(\mathrm{Cr}+2 \mathrm{Mo}-16)^{2}}{12}+\frac{\mathrm{Mn}}{2}+30(0.10-\mathrm{C})+12 \\
\mathrm{~F}=(\mathrm{Ni})_{\max }-\% \mathrm{Ni}
\end{gathered}
$$

When ferrite amount in the structure is limited to 3-4\%, austenite particles will not be surrounded by 

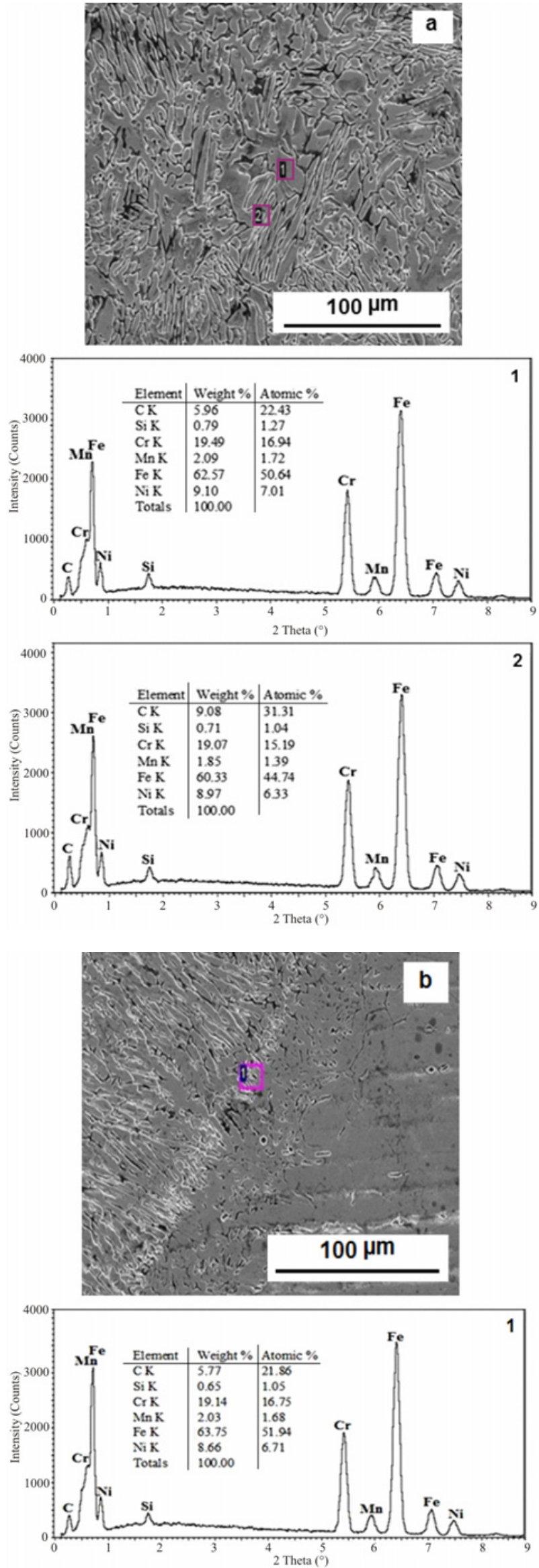
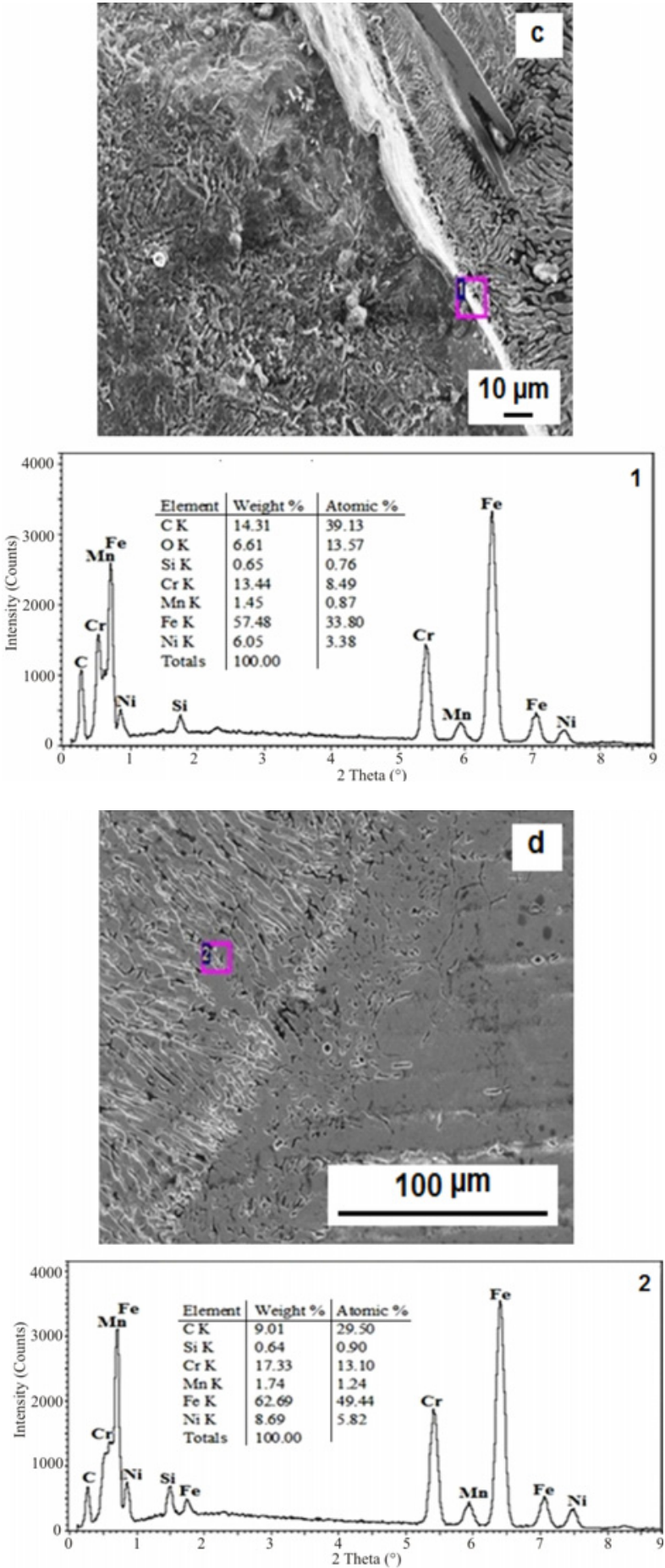

Fig. 4a-d. The SEM micrographs and EDS analyses points across the welding interface of the sample S2.

ferrite and the risk of brittleness will be prevented. On the other hand, if ferrite amount exceeds $12 \%$, the ability of flexibility will rapidly decrease. During the welding, if heat input is kept in a narrow region, hardening of the weld pool will occur in a larger region, and as a result, HAZ region will also be narrower [10, 11]. Thanks to the narrowing of welding seam geome- 


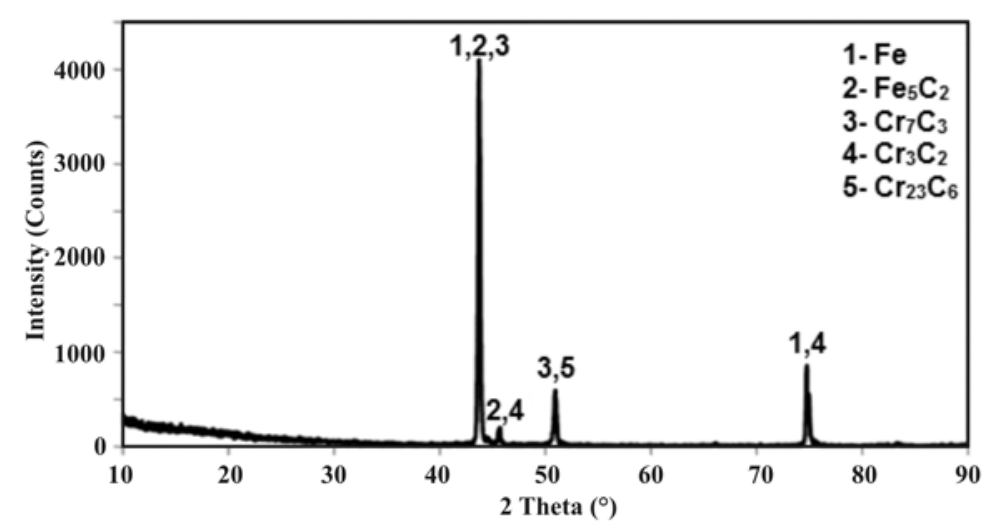

Fig. 5. The results of XRD analyses of sample S2.

try and HAZ region, hot cracking sensitivity decreases and grain size remains fine in stainless steel materials. Residual voltage in the welding region decreases due to the concentration of energy intensity of the heat input to a narrow area [12-14]. When $\mathrm{Cr}_{\text {eq }} / \mathrm{Ni}_{\text {eq }}$ ratio is lower than 1.5 , the microstructure turns into austenite. In the case of the absence of $2-3 \% \delta$-ferrite in the structure, cracking tendency occurs in the material. Thus, the presence of a certain amount of ferrite in austenite is beneficial as it decreases cracking tendency. When compared to some elements which cause cracking, the residual elements which ruin purity dissolve in ferrite rather than austenite. In the case of ferrite of a certain amount in dendrites in the composition of molten metal, the elements which can form embrittlement phases are locked in ferrite. Furthermore, ferrite has a better deformation capacity than austenite. Thanks to this property, a certain amount of ferrite will be beneficial to eliminate tensile strength. Thus, the risk of micro-cracks will be decreased. EDS analysis results of S2 sample welded by MIG welding method are respectively presented in Figs. 5a-c. EDS analysis of welding shows that chrome and carbon element diffusion occurs from AISI 304 austenitic stainless steel material towards AISI 1040 carbon steel material and carbon diffusion occurs from AISI 1040 steel towards AISI 304 steel at the same distance. Carbon and chrome diffusion increases depending on the increasing heat input.

\subsection{Microhardness test results}

Microhardness test results of S1 and S2 welding processes are presented in Fig. 6. Test results show that hardness amount is high in the seam region. Analysis of welding zone hardness of welded samples showed that the highest hardness values in all samples were measured in the weld metal. Analysis of HAZs of welded samples showed that both HAZs were harder than the base material and less hard than the weld metal. Comparison of welding methods showed that

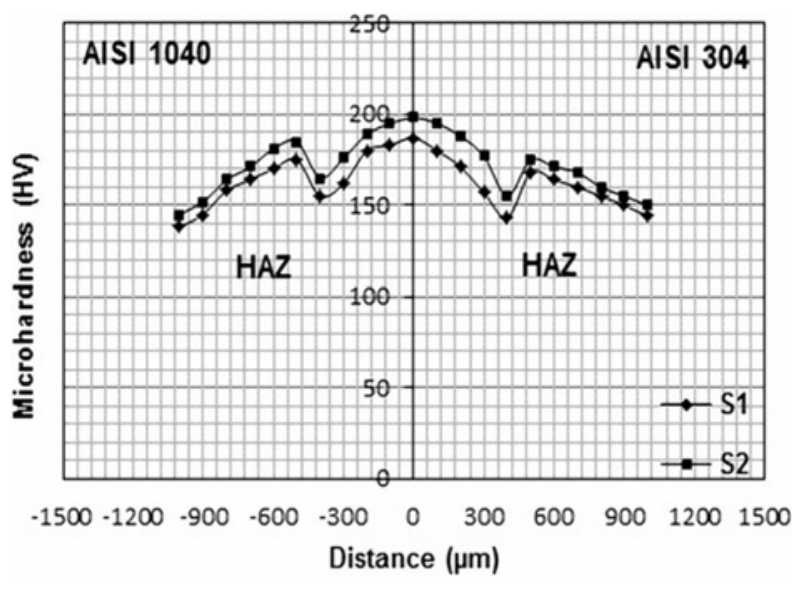

Fig. 6. Distribution of microhardness across the weld interface.

large grains occurred and hardness values decreased in the welding which used manual (GMAW) method due to increased heat input and longer hardening time. Weld metals of the welding processes which used synergic controlled pulsed (P-GMAW) welding method had a fine-grained structure due to low heat input and fast hardening. It was reported in the literature that the fine-grained structure in weld metal had a positive impact on the mechanical properties of the weld metal. Weld additional metal increased hardness. This increase was caused by high (Mo) element in the chemistry of the welding electrode. Molybdenum is added to the weld metal to increase strength and toughness.

High hardness values in welding zone can depend on the content of the used additional metal. The residual voltage in the welding area increases in parallel to the heat input. Hardness values can also increase due to residual stress $[10,11]$. It was found that welding zone has a hardness value of approximately 235 Vickers in the welding processes which used GMAW and P-GMAW methods. Based on this value it can be stated that sigma $(\sigma)$ phase with 700-800 Vickers 

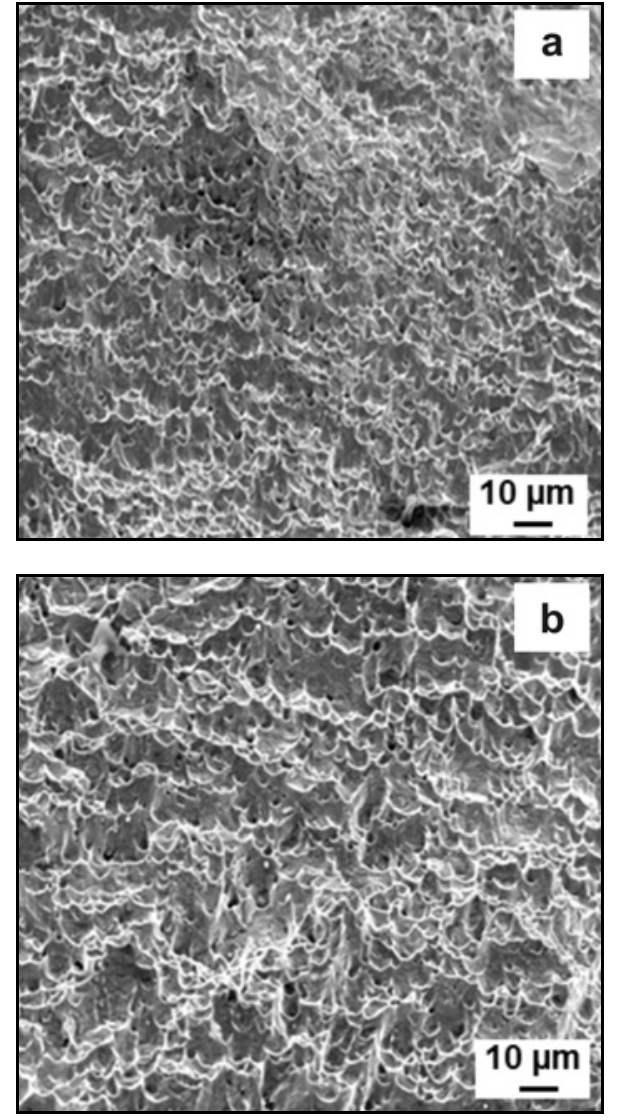

Fig. 7a,b. SEM micrographs of fracture surface after notch impact test of welded sample S2.

hardness value did not occur. In addition, it can be stated that presence of more than $10 \%$ nickel in additional metals prevents the formation of sigma phase at a ratio to affect hardness.

\subsection{Impact test results}

According to Charpy, the impact test result of S1 sample was $18.50 \mathrm{~J}$; S2 sample had 36.15 J Charpy impact resistance value. This impact resistance difference in GMAW and P-GMAW welding occurs from different heat inputs during the welding process depending on the welding method. The heat applied to the materials during welding mostly affects $\mathrm{HAZ}$ and grain coarsening increases in this region due to increased heat input. As one might know, large-grained structures always have lower resistance than finegrained structures. Any dislocation in the material moves only within a short distance before encountering a grain limit and thus increases the resistance of the materials. This rule is known as Hall-Petch equation in the literature [14]. Hall-Petch equation $\sigma_{\mathrm{y}}=$ $\sigma_{0}+K / d^{1 / 2}$ (where $\sigma_{\mathrm{y}}$ is tensile yield stress, $\sigma_{0}$ is shear stress, $K$ is a constant for a particular material, and $d$ is grain diameter) explains the relationship between shear stress and grain size in metallic materials. It was reported in the literature [15] that grain coarsening during welding was related with temperature value and the time maintained at this temperature and that it caused loss of toughness in heat affected zone. Therefore, hardness values of welded metals obtained by synergic controlled pulsed (P-GMAW) flow were higher than those of the metals obtained by manual (GMAW) method. In addition to ductility and toughness, corrosion and heat cracking resistance of the materials are affected by the $\delta$-ferrite amount which occurs in the weld metal in welding of austenitic stainless steels. Therefore, the $\delta$-ferrite amount should be maintained at a certain value. Lin et al. [10] reported that when the $\delta$-ferrite amount was $5-10 \%$, it had a positive impact on the increase of resistance and toughness. The rupture occurred in carbon steel base metal side and in the large-grained region of HAZ adjacent to welding melting limit in all of the samples.

\subsection{Fracture surface analysis}

Fracture surface images of welding processes following impact test are presented in Fig. 7. Analysis of fracture surface images showed that typical fracture morphology of the austenite stainless steel addition metal showed a hole mesh in a simple form. This indicates that fracture was ductile in impact test and that welded material was more resistant to dynamic loads.

\section{Conclusions}

AISI 304/AISI 1040 steel pair was welded using manual (GMAW) and synergic controlled pulsed (P-GMAW) welding methods using AISI 316L additional metal. The following results were obtained by this procedure:

1. It was found that in welding processes with pulsed current, heat input applied on the parts was lower due to upper and lower ampere.

2. Microstructure analysis showed that weld metal which melted and hardened was composed of equiaxial dendritic grains. In welding which used MIG method, grain coarsening was significant due to high heat input in both sides of the welding area in the base material and low hardening.

3. The weld metal contained a certain amount of $\delta$-ferrite. Scheaffler presented that delta ferrite ratio showed 9-11\% variation according to weld metal and the used welding method. Furthermore, it was observed that microstructure in welding was composed of austenite + ferrite phases.

4. It was found that weld metal hardness values obtained from pulsed flow were higher than from direct flow due to rapid hardening.

5. Impact test of the samples welded using P- 
GMAW welding method showed that it gave the highest fracture energy value. The use of pulsed current in welding procedure has a positive impact on the Charpy impact resistance of the weld metal when compared to direct flow.

6 . In all of the welded samples, fracture occurred in AISI 1040 steel material side of the welded joint and in the large-grained region of HAZ.

\section{References}

[1] Kotecki, D. J.: ASM Handbook. Welding of Stainless Steel. Welding and Brazing and Soldering. Volume 6. Materials Park, ASM International 1993.

[2] Palani, P. K., Murugan, N.: Int. J. Adv. Manuf. Technol., 30, 2006, p. 669. doi:10.1007/s00170-005-0101-2

[3] Praveen, P., Yarlagadda, P. K. D. V., Kang, M. J.: J. Process. Tech., 164, 2005, p. 1113. doi:10.1016/i.jmatprotec.2005.02.100

[4] Teker, T.: Arch. Metall. Mater., 58, 2013, p. 1029. doi:10.2478/amm-2013-0122

[5] Madhusudhan Reddy, G., Gokhale, A. A., Prasad Rao, K.: Mater. Sci. Technol., 14, 1998, p. 61. doi:10.1179/mst.1998.14.1.61
[6] Palani, P. K., Murugan, N.: J. Process. Tech., 172, 2006, p. 1. doi:10.1016/i.jmatprotec.2005.07.013

[7] Liao, M. T., Chen, P. Y.: Mater. Chemistry Physics, 55, 1997, p. 145. doi:10.1016/S0254-0584(98)00134-5

[8] Lothongkum, G., Viyanit, E., Bhandhubanyong, P.: J. Process. Tech., 110, 2001, p. 233. doi:10.1016/S0924-0136(00)00875-X

[9] Durgutlu, A.: Mater. Des., 25, 2004, p. 19. doi:10.1016/i.matdes.2003.07.004

[10] Lin, Y. C., Chen, P. Y.: Mater. Sci. Eng. A, 307, 2001, p. 165. doi:10.1016/S0921-5093(00)01821-9

[11] Juang, S. C., Tarng, Y. S.: J. Process. Tech., 122, 2002, p. 33. doi:10.1016/S0924-0136(02)00021-3

[12] Tseng, K. H., Chou, C. P.: J. Process. Tech., 123, 2002, p. 346. doi:10.1016/S0924-0136(02)00004-3

[13] Gülenç, B., Develi, K., Kahraman, N., Durgutlu, A.: Int. J. Hydrogen Energ., 30, 2005, p. 1475. doi:10.1016/i.ijhydene.2004.12.012

[14] Karci, F., Kaçar, R., Gündüz, S.: J. Process. Tech., 209, 2009, p. 4011. doi:10.1016/i.jmatprotec.2008.09.030

[15] Teker, T., Kurşun, T.: Mater. Manuf. Process., 26, 2011, p. 926. doi:10.1080/10426914.2011.551909

[16] Kanga, B. Y., Prasad, Y. K. D. V., Kang, M. J., Kim, H. J., Kim, I. S.: J. Process. Tech., 209, 2009, p. 4722. doi:10.1016/j.jmatprotec.2008.11.035 